\title{
O AMBIENTE CONSTRUÍDO E A OCORRÊNCIA DE CRIMES: UMA ANÁLISE EM ESTACIONAMENTOS DE CAMPUS UNIVERSITÁRIO
}

\section{THE BUILT ENVIRONMENT AND THE OCCURRENCE OF CRIMES: AN ANALYSIS IN UNIVERSITY CAMPUS PARKING LOTS}

\author{
Mariana Soares 1 \\ Universidade Federal de Santa Catarina, Florianópolis, SC, Brasil, mariana_soa@hotmail.com \\ Gabriel George Grosskopf 2 \\ Universidade Federal de Santa Catarina, Florianópolis, SC, Brasil, gabreorge@gmail.com \\ Julia Roberta Eli ${ }^{3}$ \\ Universidade Federal de Santa Catarina, Florianópolis, SC, Brasil, julia.eli96@gmail.com \\ Renato Tibiriçá de Saboya 4 \\ Universidade Federal de Santa Catarina, Florianópolis, SC, Brasil, rtsaboya@gmail.com \\ Fernando Barth ${ }^{5}$ \\ Universidade Federal de Santa Catarina, Florianópolis, SC, Brasil, fernando.barth@ufsc.br
}

\section{Resumo}

Embora haja um grande número de estudos que analisam a relação entre a forma urbana e arquitetônica e a ocorrência de crimes, estudos específicos em ambientes universitários ainda são raros. Neste trabalho, são analisados dois pares de estacionamentos no campus principal da Universidade Federal de Santa Catarina (UFSC), em Florianópolis, para verificar se a visibilidade, permeabilidade, nível de apropriação e diversidade de uso do solo podem ser fatores explicativos de uma maior ou menor ocorrência de crimes nesses locais. Eles foram escolhidos por apresentar, em cada par, quantidades semelhantes de vagas e quantidades contrastantes de crimes, sendo um estacionamento com alta e o outro com baixa ocorrência. A análise comparativa foi feita com base em levantamentos in loco, observação e elaboração de mapas. Os resultados indicam que a visibilidade e permeabilidade são efetivamente importantes para diminuir a ocorrência de crimes. Por outro lado, a quantidade de pessoas em cada local, por si só, não foi capaz de explicar as diferenças nas taxas de crimes, a não ser quando foi considerada sua distribuição ao longo do dia e a visibilidade a partir dos principais caminhos para os estacionamentos. Quanto aos usos do solo, os resultados mostraram-se contrários à crença disseminada entre arquitetos e urbanistas de que maior diversidade estaria relacionada a menor número de ocorrências criminais. As conclusões trazem elementos para fomentar os debates, planos e intervenções em campi universitários sob a lógica da segurança.

Palavras-chave: Campus universitário. Ocorrência de crimes. Visibilidade. Vigilância Natural. Usos do solo.

\begin{abstract}
Although there are many studies about the relationship between urban and architectural form, and the occurrence of crimes, studies that deal specifically with university environments are still rare. In this work, we analyze two pairs of parking lots on the main campus of the Federal University of Santa Catarina (UFSC), in Florianópolis, to ascertain if visibility, permeability, number of users and land use diversity are relevant explanatory factors of higher or lower quantities of crime occurrences in these areas. Each pair comprised one parking lot with high and other with low crime rate, both with similar amounts of parking spots. Field surveys, observations, and maps supported a comparative analysis. The results indicate that visibility and permeability are effectively crucial in reducing the occurrence of crimes. On the other hand, the sheer number of people in each place was not able to explain the differences in crime rates, except when its distribution throughout the day and the visibility provided by the primary circulation paths to the parking lots were taken into account. As for land uses, the results were contrary to the widespread belief among architects and urbanists that greater diversity is related to a lower number of criminal occurrences. The conclusions bring forth essential aspects to be considered in debates, masterplans and spatial interventions on university campuses.
\end{abstract}

Keywords: University campus. Crime occurrence. Visibility. Natural surveillance. Land use.

How to cite this article:

SOARES, Mariana et al.. O ambiente construído e a ocorrência de crimes: uma análise em estacionamentos de campus universitário. PARC Pesquisa em Arquitetura e Construção, Campinas, SP, v. 8, n. 2, p. 102-116, jun. 2017. ISSN 1980-6809. Disponível em:

<https://periodicos.sbu.unicamp.br/ojs/index.php/parc/article/view/8649893>. Acesso em: 14 dez. 2017.

doi:http://dx.doi.org/10.20396/parc.v8i2.8649893. 


\section{Introdução}

O medo de ser vítima de um crime tem afetado cada vez mais a qualidade de vida da população brasileira, alterando o modo de pensar edificações e o uso dos espaços urbanos. O sentimento de insegurança provocado pelo contínuo aumento da criminalidade gera uma tendência ao isolamento que tem alterado a configuração tradicional das cidades ao substituírem-se as casas voltadas para a rua e as ruas com presença de uso misto de moradias, comércio e serviços, por condomínios fechados, horizontais e verticais, isolados da rua por meio de barreiras físicas e/ou visuais e criação de vizinhanças monofuncionais (CALDEIRA, 2000). Tal postura se reflete, portanto, em projetos arquitetônicos que afetam diretamente a relação das pessoas com os espaços públicos, em especial os de convivência coletiva.

Jacobs (2001), já no início da década de 1960, analisou o comportamento social da população urbana, especialmente o papel e o cuidado dos moradores com o espaço comum. Argumentou que aspectos da configuração dos espaços urbanos - como o uso diversificado, a existência de atrativos para as pessoas circularem nas ruas e a promoção da vigilância natural nos espaços públicos - aquela exercida pelos próprios usuários do local, denominados de os "olhos da rua" - são condições fundantes para a segurança de um espaço. Oscar Newman, na década de 1970, introduziu o conceito de "espaço defensável", associando a segurança à territorialidade, à vigilância e ao controle /apropriação das pessoas sobre os espaços em que habitam e circulam (NEWMAN, 1976).

Uma longa tradição, que pode ser agrupada sob a denominação de criminologia ambiental, se desenvolveu a partir desses e outros estudos seminais, apoiando-se em alguns princípios básicos que são, também, adotados por este trabalho: entre eles, destacamos a teoria da escolha racional e as atividades rotineiras. A primeira entende que ofensores são agentes que usam dados ambientais para tomarem decisões sobre se - e como - engajar-se em um crime (CLARKE; CORNISH, 2010; WILCOX; LAND; HUNT, 2003; WORTLEY; MAZEROLLE, 2008). Assim, a teoria da escolha racional enfatiza o papel da percepção do criminoso sobre o local, analisando os custos e benefícios que este oferece. A abordagem da atividade rotineira, por sua vez, argumenta que o evento criminal resulta da conjunção, no tempo e no espaço, de três fatores (COHEN; FELSON, 2010): a) um indivíduo ou grupo de indivíduos motivados; b) um alvo que desperte o interesse e esteja acessível; e c) a ausência de guardiões capazes de impedir o crime.

Mais recentemente, pesquisas brasileiras no campo da Arquitetura e da Segurança Pública têm destacado que a forma urbana deve ser tratada como uma variável ativa capaz de oportunizar comportamento (QUINTANA,
2013; BONDARUK, 2007; SABOYA; BANKI; SANTANA, 2016), alertando que o planejamento urbano deve incorporar em seus projetos arquitetônicos, urbanísticos e paisagísticos, estratégias espaciais visando à segurança pública, uma vez que as condições locais do espaço e a sua relação com as edificações poderiam influenciar nos níveis de criminalidade no espaço urbano. Estudos de caso com diferentes abordagens e procedimentos metodológicos (NEWMAN, 1976; ZANOTTO, 2002; VIVAN, 2012; QUINTANA, 2013) têm indicado que o uso do solo, o movimento de pessoas e a forma dos edifícios podem gerar impacto na vitalidade e, consequentemente, na segurança dos espaços públicos.

Mais especificamente, esses aspectos podem mudar a percepção de um possível infrator quanto ao balanço de recompensas ou punições envolvidas em suas decisões. Assim, podem fazer com que as consequências percebidas de cometer um crime sejam mais desvantajosas, dolorosas ou perigosas do que o valor atribuído às motivações, ganhos pessoais e/ou prazeres obtidos em cometê-lo (WILCOX; LAND; HUNT, 2003).

Sendo assim, a possibilidade ou expectativa de vigilância natural é, provavelmente, um dos aspectos mais importantes a serem levados em consideração pelo infrator. No estudo da relação entre a prevenção de um crime e o desenho urbano, o destaque à vigilância natural tem sustentado fortemente premissas que estão associadas com a permeabilidade, com o uso misto e com a elevada densidade (NEWMAN, 1976; JACOBS, 2001; COZENS; SAVILLE; HILLIER, 2005, entre outros), todos eles supostamente elevando a quantidade de usuários e, em consequência, os níveis de vigilância natural. No entanto, alguns estudos têm demonstrado que a quantidade de espectadores em uma cena urbana não está diretamente relacionada à probabilidade de intervenção desses espectadores sobre uma eventual ocorrência criminal (NEWMAN, 2003; SORENSEN, 2003). Assim, em áreas com mais passagem de pessoas que não se conhecem e não possuem um senso de comunidade, as taxas de crime podem aumentar. Contudo, nesses casos, a probabilidade de ser identificado e/ ou detido ainda é um fator a ser considerado pelo infrator.

Entretanto, grande parte dos estudos realizados até o momento tratam prioritariamente da relação entre configuração espacial e criminalidade nas cidades, não abordando locais que possuem configurações específicas e características próprias, como os campi universitários. A estrutura desses lugares, em geral composta por espaços públicos abertos contendo áreas de lazer (praças, quadras de desportos e outros) e edificações (salas, laboratórios, bibliotecas, auditórios, centros culturais, cafeterias, entre outros), estimula diferentes tipos de interações sociais entre as pessoas que circulam em seu interior. 
Considerando que os problemas que ocorrem nas cidades, como é o caso da criminalidade, também podem ocorrer nos campi, é importante conhecer melhor a relação entre a configuração espacial de campi universitários e as ocorrências criminais neles registradas. Se, por um lado, contam com uma comunidade de usuários menos heterogênea que os espaços urbanos em geral e, normalmente, vigias e câmeras de vigilância, por outro possuem: a) alto poder de atração de pessoas, gerando padrões intensos de movimento, especialmente em horários de entrada e saída dos turnos escolares, o que pode gerar certo anonimato; b) alvos atrativos, especialmente no que diz respeito a equipamentos eletrônicos portáteis, tais como aparelhos celulares e notebooks; c) no caso de campi de universidades federais, dificuldade de monitoramento e atuação por parte das polícias estaduais. Entretanto, o debate sobre a relação entre ocorrências criminais nos campi e o espaço da instituição tem privilegiado somente questões como a dificuldade de circulação pelo campus, falta de iluminação adequada, terceirização da segurança e precariedade do trabalho da Guarda Universitária, sem abordar com maior profundidade a configuração espacial desses locais. Entender se e como esta pode interferir na ocorrência de crimes pode contribuir na elaboração e reformulação de planos de desenvolvimento institucional e respectivos planos diretores que englobem aspectos de segurança.

Assim, este artigo analisa o impacto de fatores relacionados à vigilância natural (visibilidade; permeabilidade; quantidade de pessoas transitando pelo local e variedade de uso do solo) na ocorrência de crimes de furto e roubo de veículos em estacionamentos de um campus universitário.

\section{Premissas}

Algumas premissas sobre a relação entre configuração espacial e ocorrência de crimes em espaços urbanos nortearam este trabalho, e foram testadas em um estudo de caso:

- Ocorrências de crimes são mais frequentes em áreas que apresentam uma configuração espacial com menor campo de visão, ou seja, com maior número de barreiras visuais, o que acarretaria em menor intervisibilidade entre as pessoas;

- Locais com maior permeabilidade e com maior número de pessoas transitando tendem a ter menos ocorrências criminais, por ampliarem as possibilidades de vigilância natural;

- Crimes, geralmente, tendem a acontecer em locais com menor diversidade de uso do solo, pois esses locais seriam menos utilizados e, portanto, possuiriam menor vigilância natural.

\section{Método}

Com o objetivo de analisar especificamente a relação entre a configuração espacial e a ocorrência de crimes de furto e roubo de veículos em estacionamentos do campus Reitor João David Ferreira Lima, entre 2010 e 2015, adotamos os seguintes procedimentos metodológicos para cada uma das etapas da pesquisa.

\section{Seleção dos locais de análise}

A partir de dados obtidos junto ao departamento de segurança da UFSC, contabilizamos e especializamos a quantidade dos crimes de furto e roubo registrados no campus Reitor João David Ferreira Lima, entre 2010 e 2015, identificando locais com maior incidência de crimes. Aproximadamente 15\% dos locais identificados como pontos quentes para furto e roubo apresentavam de 6 a 31 ocorrências. Para o presente estudo foram selecionados dois pares de estacionamentos, sendo cada um deles composto por: a) um estacionamento com alto número de ocorrências criminais, (entre 6 e 31 ocorrências); e b) um estacionamento com pouca ou nenhuma ocorrência $\left(\begin{array}{lll}0 & \text { a } & 2\end{array}\right)$. Isso foi feito devido à disponibilidade de dados sobre ocorrências, que não contavam com precisão espacial suficiente; os estacionamentos, então, funcionaram como referência espacial relativamente precisa, permitindo comparar as diferenças e semelhanças encontradas ao serem analisadas as variáveis pesquisadas neste artigo (ao contrário, por exemplo, de uma ocorrência marcada simplesmente como tendo acontecido no "Centro Tecnológico"). Como parâmetro de comparação, selecionamos estacionamentos que apresentassem número semelhante de vagas, para evitar possíveis distorções causadas por diferentes quantidades de alvos em cada um dos membros de um mesmo par.

A Figura 1 mostra os pares selecionados. Aqueles com índices maiores de crime de furto de/em veículos estão identificados pela letra A (referente a "Allto índice de ocorrências criminais"), enquanto que os dois com índices menores desse tipo de crime estão identificados pela letra B (referente a "Baixo índice de ocorrências criminais"). Dentre os estacionamentos representados pelos tons de cor azulados, o 1A (Estacionamento do Centro de Ciências da Educação - CED) apresenta alto índice de quantidade de furtos e o 1B (Estacionamento da Biblioteca Universitária - BU) apresenta baixo índice de quantidade de furtos, embora ambos possuam número semelhante de vagas. Os outros dois estacionamentos que foram comparados seguiram a mesma representação: 2A (Estacionamento do Centro de Ciências Jurídicas - CCJ) e 2B (Estacionamento da Reitoria), identificados com tons alaranjados. 
Figura 1. Localização dos quatro estacionamentos selecionados para análise no campus Reitor João David Ferreira Lima

MAPA DE LOCALIZACÃO DOS PARES DE ESTACIONAMENTOS 1A:1B E $2 A: 2 B$

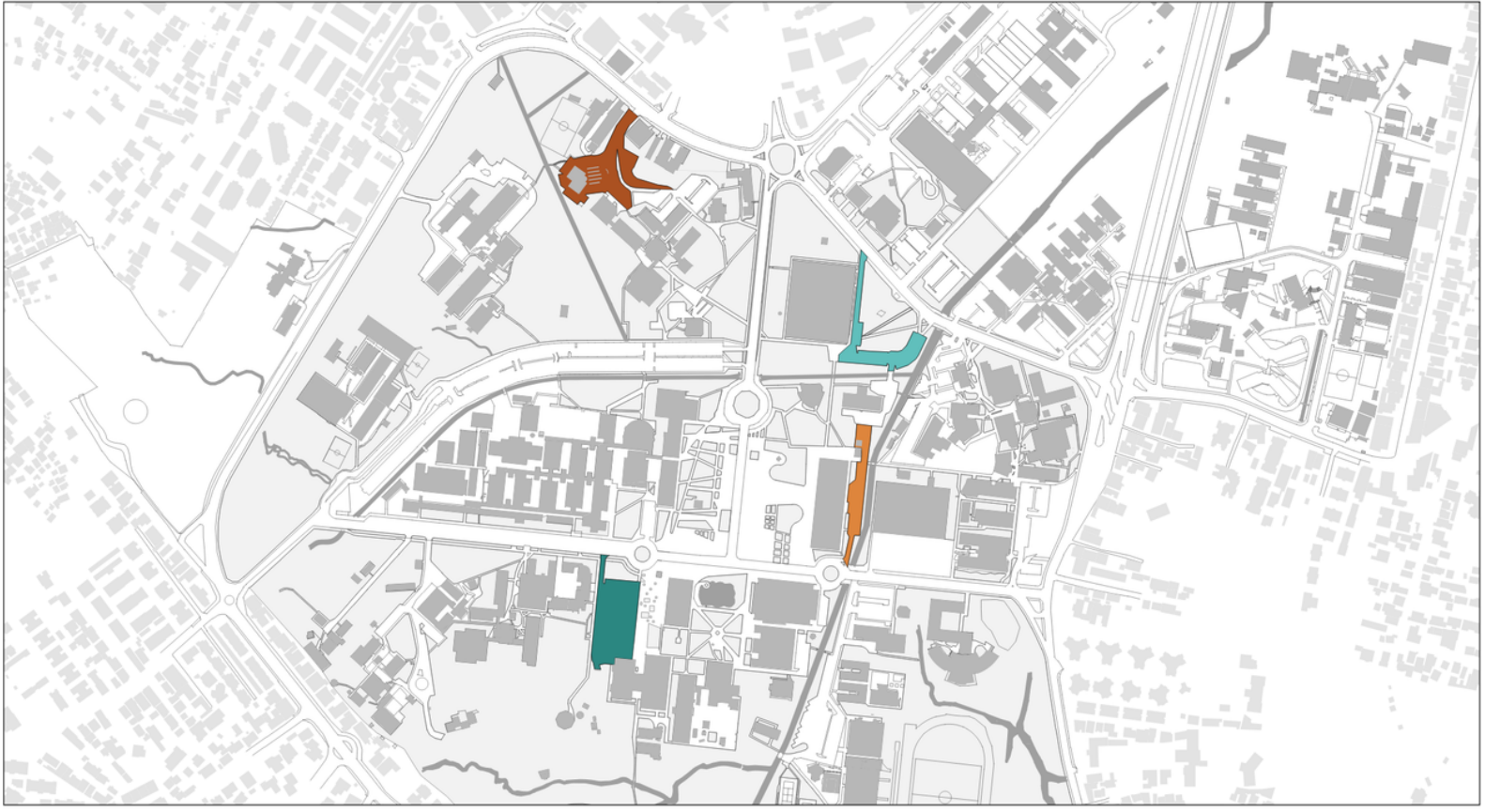

Legenda

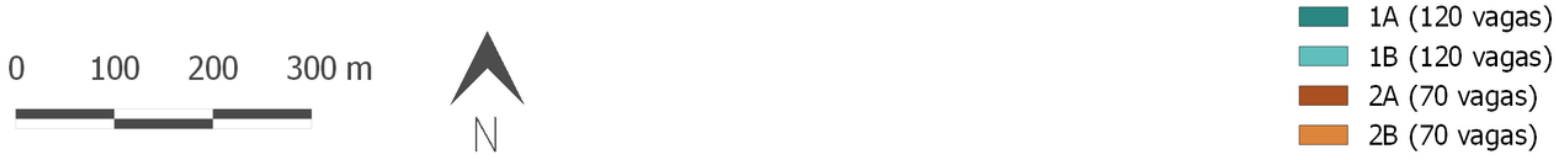

Fonte: Os autores, editado da Ortofoto da Secretaria de Estado do Desenvolvimento Sustentável SDS/SC, 2013

Figura 2. Estacionamentos $1 \mathrm{~A}, 1 \mathrm{~B}, 2 \mathrm{~A}$ e $2 \mathrm{~B}$

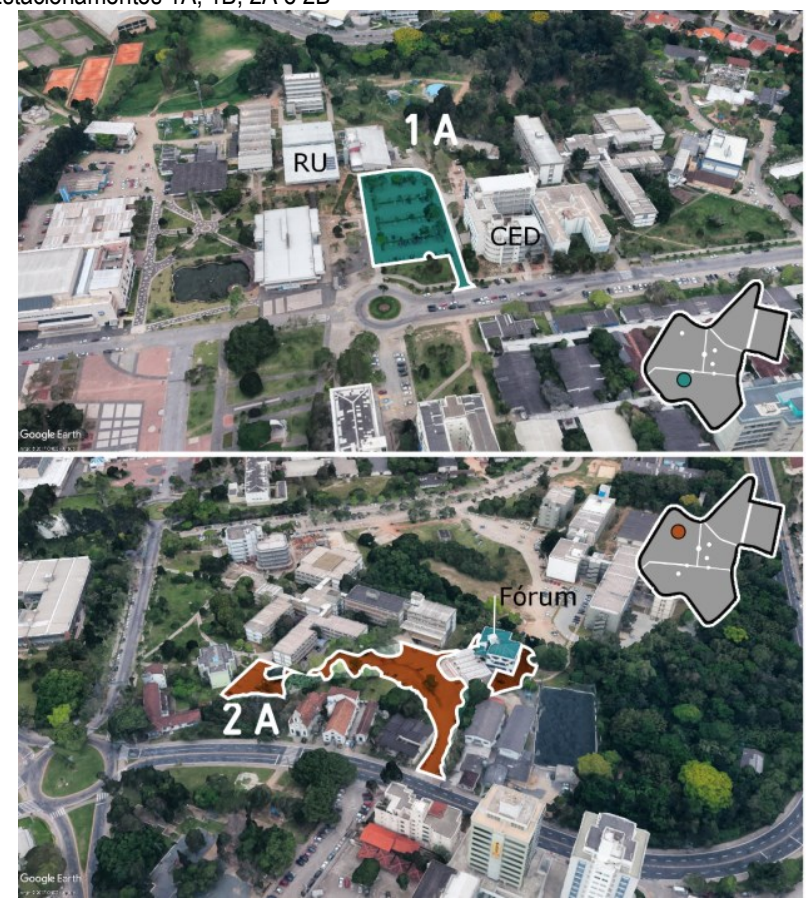

Fonte: Os autores, em 2017, com base em imagens do Google Earth

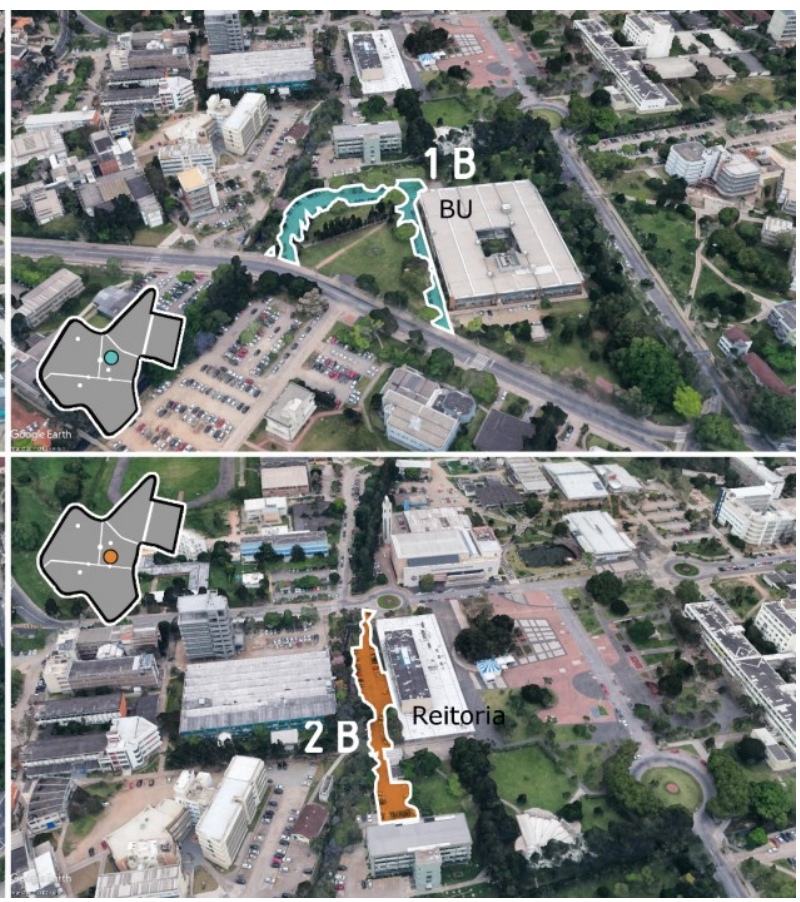

Na Figura 2 são apresentados os pares de estacionamentos comparados, juntamente com seus entornos imediatos.

Variáveis de interesse 
Neste estudo analisamos quatro variáveis: visibilidade; permeabilidade; quantidade de pessoas transitando pelo local (subdividida em quantidade de pessoas e porcentagem da área do estacionamento ocupada por essas pessoas) e variedade de uso do solo. As análises foram realizadas por meio de levantamentos de campo e elaboração de mapas que possibilitaram a quantificação desses aspectos. Como variável de controle, estudamos também a iluminação desses locais e a existência de recursos de vigilância.

A visibilidade foi quantificada através da área da isovista em cada ponto do espaço analisado. A isovista é um polígono que representa a área visível a partir de um ponto. Portanto, ela também oferece uma estimativa aproximada do quanto um ponto pode ser visto a partir de outros pontos no sistema analisado, isto é, do quão exposto ao escrutínio de outras pessoas ele está. O cálculo das isovistas é feito com base em uma malha reticular uniforme, na qual a área da isovista a partir do centro de cada célula é calculada. No caso deste trabalho, adotamos uma célula de $3 \times 3 \mathrm{~m}$.

A permeabilidade foi representada pela medida de integração (HILLIER et al, 1993). No caso da análise global, o cálculo foi feito através de linhas axiais, que são uma representação simplificada das maiores linhas de movimento e visão de um sistema de espaços abertos. A integração mede o quão próxima uma linha está de todas as outras, em média, em termos de mudanças de direção. Linhas mais próximas das outras são ditas rasas e de alta integração; linhas mais distantes, normalmente aquelas que ficam na periferia do sistema, são ditas profundas e segregadas. No caso das análises locais, o mesmo cálculo de profundidade é feito para as células das retículas.

Para determinar a quantidade de pessoas no local, foram tiradas fotografias simultâneas de cada estacionamento, em diferentes posições, de forma a cobrir toda a área do local de análise, considerando também seu entorno imediato. As fotografias foram tiradas durante uma semana, em diferentes períodos: matutino, vespertino e noturno, alternando-se entre horários letivos e horários de pico. Com as fotografias foi possível contar a quantidade de usuários presentes em cada estacionamento no momento do registro, além de mapear suas localizações no espaço. Nesse aspecto, foi calculada também a proporção, em porcentagem, do espaço analisado que possuía efetivamente pessoas utilizando.

Para determinar a variedade de usos do solo, foram consideradas as edificações adjacentes aos estacionamentos que têm seu acesso relacionado à área selecionada para análise. Como classificação, foram estabelecidas as seguintes categorias: US (uso de sala de aula, sala de professores e auditório), UL (uso laboratorial), UA (uso administrativo), UC (uso comercial), UCV (uso convivência: centro de cultura e eventos, centro de convivência, entre outros), UM (uso misto), UR (uso restaurante universitário), UB (uso biblioteca), UMO (uso moradia), UH (usos hospital universitário), UF (uso farmácia escola), UE (uso área esportiva), UCC (uso escolar: colégio aplicação e creches), UFJ (uso fórum) e UAV (praças e parque).

Com relação às variáveis de controle, iluminação e recursos de vigilância, foi obtida a densidade de pontos de iluminação (postes de iluminação e luminárias externas) e de recursos de vigilância (câmeras de segurança e pontos de vigia) e dividida pela área do estacionamento. Também foram levantadas a porcentagem de área iluminada $\mathrm{e}$ visível por recursos de vigilância em cada estacionamento.

Outras variáveis incluídas no estudo original não serão relatadas neste trabalho, por questões de espaço. Entre elas, estão: presença de esconderijos, quantidade de portas e janelas, aparência do local, caracterização socioeconômica do entorno e nível de renda dos alunos por centro de ensino.

Como outras universidades brasileiras, o campus da Universidade Federal da Santa Catarina encontra-se em malha urbana já consolidada e densamente povoada, possuindo locais em que são maiores ou menores as relações com o seu entorno. No entanto, pelo campus apresentar acessos específicos, não permitir que veículos utilizem suas vias internas para cruzar o campus (possuindo cancelas nas vias que poderiam realizar esse cruzamento) e apresentar áreas verdes na maioria do seu entorno, consideramos apenas a área do campus para os estudos das variáveis visibilidade e permeabilidade.

\section{Resultados}

\section{Visibilidade}

Para representar as condições de visibilidade nos espaços estudados, elaboramos um mapa geral do campus central da UFSC (Figura 3), destacando a visibilidade e a proeminência visual no espaço universitário. São consideradas como barreiras de visibilidade: edificações, vegetação densa, muros ou cercamentos visualmente impermeáveis, taludes, árvores e arbustos que impedem a visão. Na Figura 3, é possível identificar áreas com maior e menor visibilidade dentro do campus por meio de coloração, cuja escala cromática varia do vermelho (maior visibilidade) ao azul (menor visibilidade), como também o valor da área média de isovista. 
Figura 3. Mapa de visibilidade de todo o campus

\section{VISIBILIDADE (ÁREA DA ISOVISTA)}

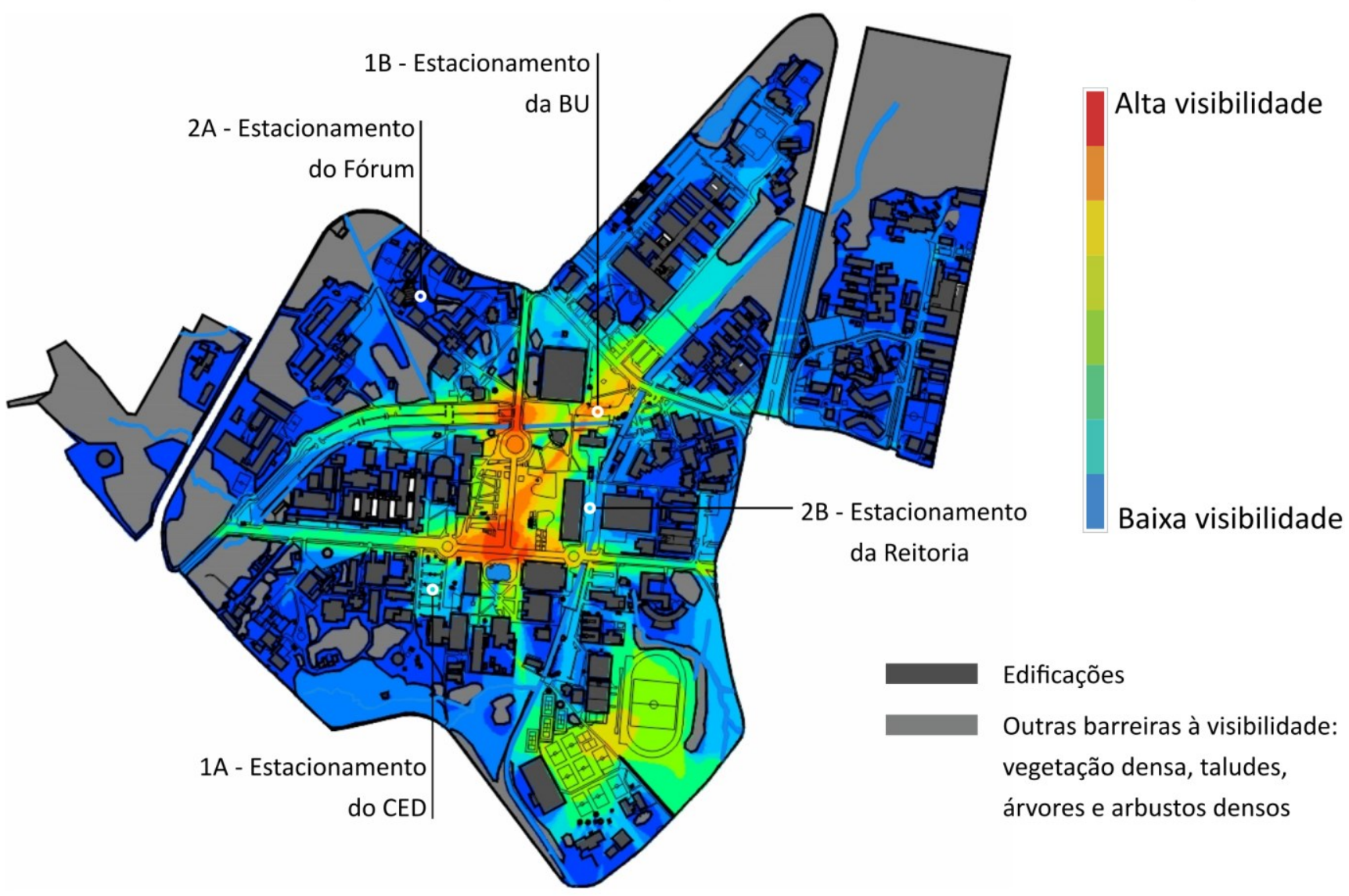

Fonte: Os autores.

Observando as Figuras 3 e 4, vemos que o estacionamento $1 \mathrm{~A}$, indicado como tendo maior ocorrência de furto e roubo de/em veículos em relação ao $1 \mathrm{~B}$, apresenta coloração mais próxima do verde e valor da área de isovista de $28.865 \mathrm{~m}^{2}$. Há pouca visibilidade em toda a área do estacionamento. Notamos também que o entorno e os acessos próximos a esse estacionamento possuem baixa visibilidade, o que poderia ser um fator relevante no momento de fuga do infrator, que encontraria, em uma distância relativamente curta, muitas oportunidades para esconder-se da visão de outras pessoas. Já o estacionamento $1 \mathrm{~B}$, identificado com menos registros de furto e roubo de/em veículos em relação ao $1 \mathrm{~A}$, está em uma área que apresenta maior visibilidade do que seu par, correspondendo a uma coloração mais próxima do vermelho e apresentando valor da área de isovista de $56.768 \mathrm{~m}^{2}$. Na mesma Figura, percebemos ainda que o entorno e os acessos próximos ao estacionamento $1 \mathrm{~B}$ possuem boa visibilidade.
Figura 4. Mapa de visibilidade detalhado do par de estacionamentos 1 MAPAS DE VISIBILIDADE (ÁREA DE ISOVISTA)

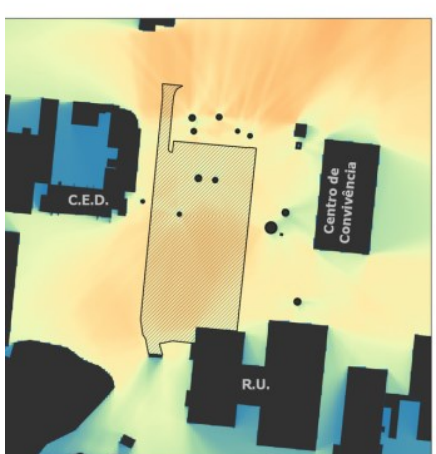

a) Estacionamento $1 \mathrm{~A}$

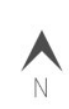

Fonte: Os autores.

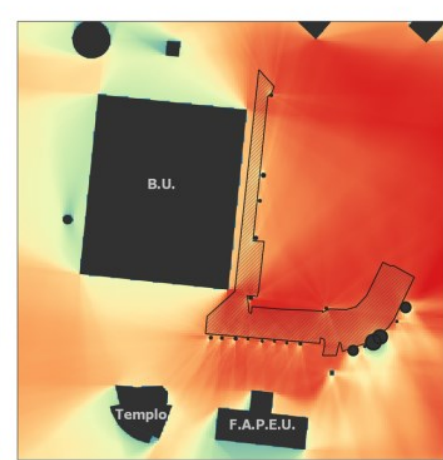

b) Estacionamento $1 \mathrm{~B}$

Área da isovista $\left[\mathrm{m}^{2}\right]$

0 (mínimo)

32679 (máximo)
Com relação aos estacionamentos mostrados nas Figuras 3 e 5 ( $2 \mathrm{~A}$ e $2 \mathrm{~B}$ ), vemos que o mesmo acontece: nelas, o estacionamento $2 \mathrm{~A}$, indicado com maior ocorrência de furto e roubo de/em veículos entre o par, apresenta 
coloração mais próxima do azul no mapa de visibilidade e valor da área de isovista de $1.592 \mathrm{~m}^{2}$. Observamos também que o entorno deste estacionamento possui baixa visibilidade se comparado ao estacionamento $2 \mathrm{~B}$ e muitas barreiras visuais. Como mencionado anteriormente em relação ao estacionamento $1 \mathrm{~A}$, isso pode ser um fator importante no momento de fuga do infrator.

Quanto ao estacionamento 2B, identificado com menor ocorrência de furto e roubo no par 2, vemos que está em uma área que apresenta maior visibilidade em relação ao estacionamento $2 \mathrm{~A}$, sendo representado por coloração entre o verde e o azul claro e apresentando valor da área de isovista de $16.874 \mathrm{~m}^{2}$. Na mesma Figura 5, ainda é possível perceber que os acessos ao estacionamento $2 \mathrm{~B}$ possuem boa visibilidade.

Figura 5. Mapa de visibilidade detalhado do par de estacionamentos 2 MAPAS DE VISIBILIDADE (ÁREA DE ISOVISTA)
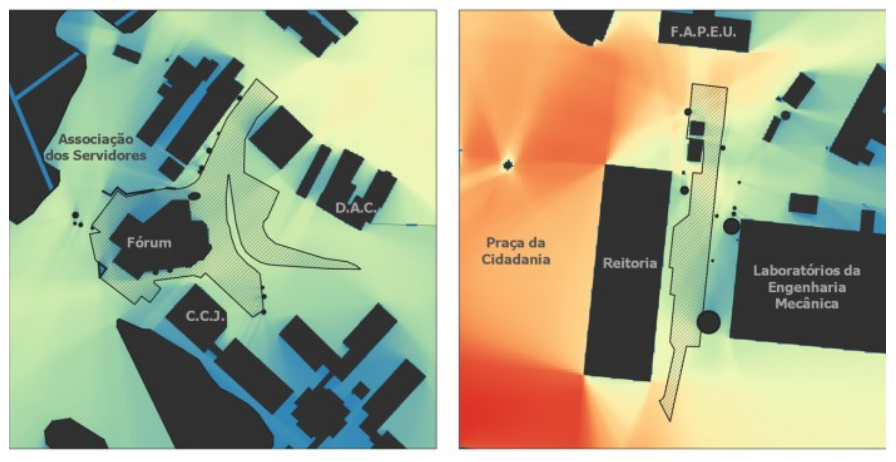

a) Estacionamento $2 \mathrm{~A}$

b) Estacionamento $2 B$

Área da isovista $\left[\mathrm{m}^{2}\right]$ $0 \quad 20 \quad 40 \quad 60 \mathrm{~m}$

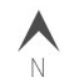

Estacionamento

0 (mínimo)

32679 (máximo)

Fonte: Os autores

O Gráfico 1 mostra essa regularidade: nos dois pares de estacionamentos, os estacionamentos 1B e 2B - que possuem menores índices de ocorrências de furto e roubo de/em veículos - apresentaram maiores valores de visibilidade do que os estacionamentos $1 \mathrm{~A}$ e $2 \mathrm{~A}$.

Gráfico 1. Valores proporcionais ${ }^{1}$ obtidos nos dois pares de estacionamentos em relação à visibilidade

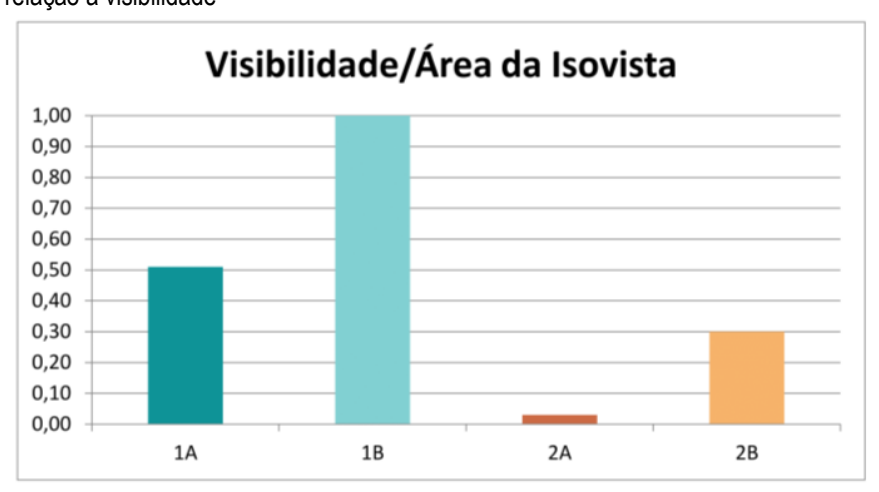

Fonte: Os autores.

\section{Permeabilidade}

Buscando representar visualmente a permeabilidade física no campus da UFSC, demarcamos as barreiras físicas existentes no campus (edificações, canteiros e elementos que impeçam o deslocamento direto). Com o uso de recursos da Sintaxe Espacial, elaboramos um mapa de linhas axiais do campus (Figura 6), considerando as vias e caminhos que demarcam e constituem o espaço universitário. No mapa, é possível notar que as linhas mais integradas estão localizadas nas áreas mais centrais do campus.

Figura 6. Mapa de linhas axiais do campus

\section{NTEGRAC ÃO AX I A L}

\section{$1 \mathrm{~B}$ - Estacionamento}

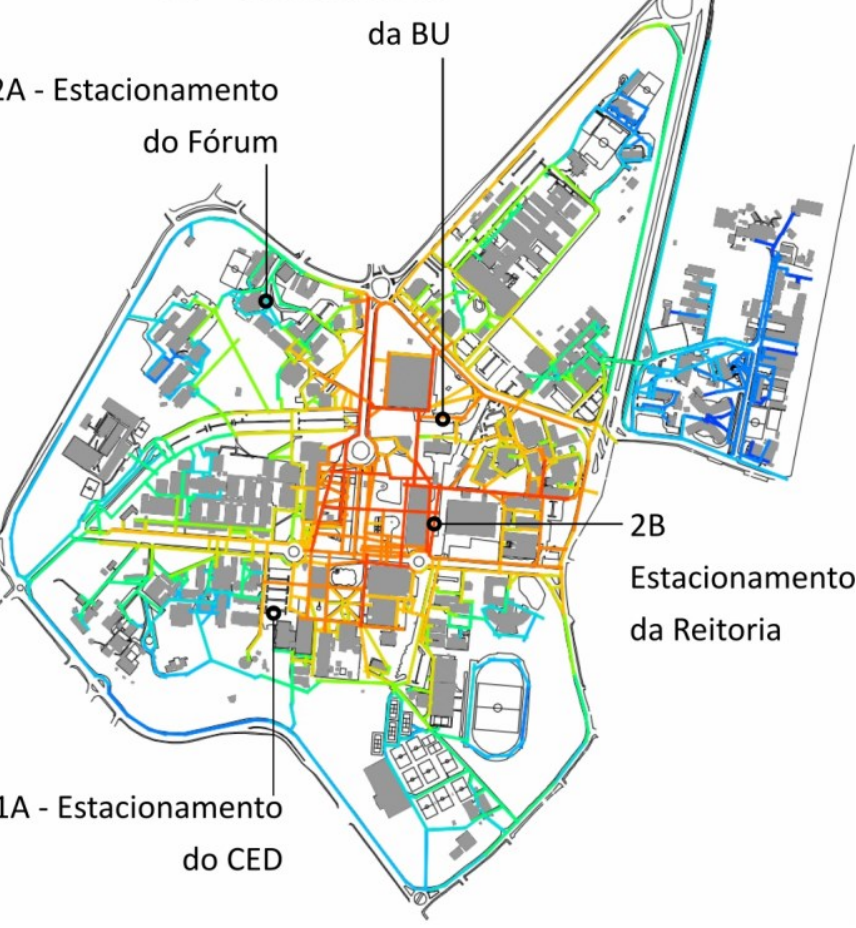

Alta
Integração

Baixa

Integração

Fonte: Os autores.

Notamos, também, que as linhas axiais que passam pelos estacionamentos $1 \mathrm{~A}$ e $1 \mathrm{~B}$ são relativamente bem integradas ao restante do campus: o estacionamento $1 \mathrm{~A}$ apresenta uma média de valor de integração de 0,705 e o estacionamento 1B uma média de valor de integração de suas linhas de 0,785 .

Quanto ao par de estacionamentos 2A e 2B, na Figura 6, é possível observar que as linhas axiais que passam pelo estacionamento $2 \mathrm{~A}$ são mais segregadas do restante do campus do que as linhas que passam pelo estacionamento $2 \mathrm{~B}$, possuindo uma média de integração de 0,471 . Na Figura 6 também é possível observar que as linhas axiais 
que passam pelo estacionamento $2 \mathrm{~B}$ são mais integradas ao restante do campus, e possuem valor de integração média de 0,812 .

No Gráfico 2, percebemos que os estacionamentos 1B e 2B, com menores índices de ocorrências de crime de furto e roubo de/em veículos, apresentaram menores valores de integração que os estacionamentos $1 \mathrm{~A}$ e $2 \mathrm{~A}$, com maiores índices de ocorrências de crime. Portanto, é possível perceber, nesses dois estacionamentos, uma relação entre menores valores de integração e maiores índices de ocorrências de furto e roubo.

Gráfico 2. Valores proporcionais obtidos nos dois pares de estacionamentos pesquisados em relação à permeabilidade

\section{Permeabilidade/Integração (média)}

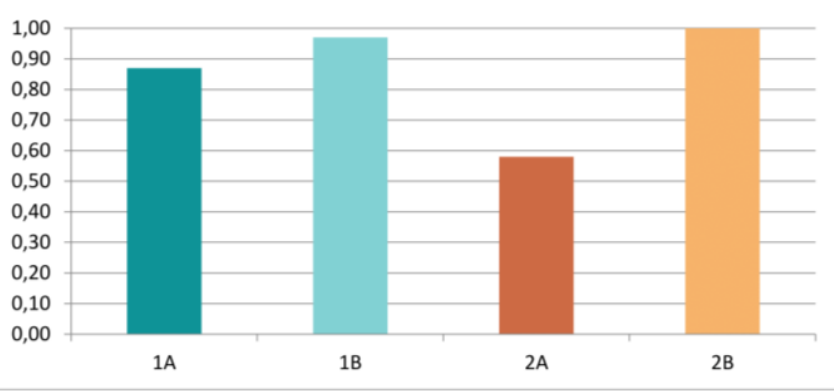

Fonte: Os autores.

\section{Quantidade de pessoas transitando pelo local}

Nas Tabelas 1 e 2 são apresentadas as informações relativas à quantidade de pessoas nos estacionamentos $1 \mathrm{~A}$ e $1 \mathrm{~B}$ e $2 \mathrm{~A}$ e $2 \mathrm{~B}$. Essas Tabelas contêm a quantidade de pessoas registradas durante cada horário e dia, bem como a porcentagem do espaço utilizada por elas.

$\mathrm{Na}$ Tabela 1, o estacionamento 1A apresenta maior concentração de pessoas e também maior apropriação do espaço por elas nos horários das 12:00 e das 18:00. Tal situação se deve à proximidade do estacionamento $1 \mathrm{~A}$ com o restaurante universitário, aberto para almoço das 11:00 às 13:30 e para jantar das 17:00 às 19:00, momentos em que há filas significativas de pessoas aguardando entrar no restaurante. Contudo, no restante do tempo a presença de pessoas nesse espaço não é tão intensa, mas mantém certa regularidade.

Analisando o estacionamento 1B na Tabela 1, percebemos que existe uma movimentação mais constante de pessoas pelo local de análise se comparado ao seu par. A proximidade do estacionamento $1 \mathrm{~B}$ da Biblioteca Universitária é certamente um fato determinante nessa situação, pois o local é utilizado durante todo o dia por uma grande quantidade de alunos.
Tabela 1. Dias, horários, número de pessoas, e porcentagem do espaço de análise utilizado pelas pessoas - Estacionamentos $1 \mathrm{~A}$ e $1 \mathrm{~B}$

\begin{tabular}{|c|c|c|c|}
\hline \multicolumn{4}{|c|}{ Estacionamento $1 \mathrm{~A}$} \\
\hline Dia & Horário & $\mathrm{N}^{\circ}$ de pessoas & Porcentagem \\
\hline Segunda-feira & $08: 00$ & 20 & $60 \%$ \\
\hline Segunda-feira & $15: 00$ & 9 & $36 \%$ \\
\hline Terça-feira & $12: 00$ & 201 & $74 \%$ \\
\hline Terça-feira & $18: 00$ & 47 & $71 \%$ \\
\hline Terça-feira & $21: 00$ & 9 & $41 \%$ \\
\hline Quarta-feira & 08:00 & 14 & $68 \%$ \\
\hline Quarta-feira & $15: 00$ & 18 & $51 \%$ \\
\hline Quinta-feira & $12: 00$ & 169 & $81 \%$ \\
\hline Quinta-feira & $18: 00$ & 31 & $58 \%$ \\
\hline Quinta-feira & $21: 00$ & 23 & $67 \%$ \\
\hline Sexta-feira & 08:00 & 21 & $35 \%$ \\
\hline Sexta-feira & $15: 00$ & 6 & $34 \%$ \\
\hline & & $\begin{array}{c}568 \\
\text { (total) }\end{array}$ & $\begin{array}{c}56 \% \\
\text { (média) }\end{array}$ \\
\hline \multicolumn{4}{|c|}{ Estacionamento 1B } \\
\hline Dia & Horário & $\mathrm{N}^{\circ}$ de pessoas & Porcentagem \\
\hline Segunda-feira & $08: 00$ & 9 & $24 \%$ \\
\hline Segunda-feira & $15: 00$ & 20 & $38 \%$ \\
\hline Terça-feira & $12: 00$ & 47 & $91 \%$ \\
\hline Terça-feira & $18: 00$ & 57 & $51 \%$ \\
\hline Terça-feira & $21: 00$ & 13 & $45 \%$ \\
\hline Quarta-feira & 08:00 & 19 & $41 \%$ \\
\hline Quarta-feira & $15: 00$ & 32 & $53 \%$ \\
\hline Quinta-feira & $12: 00$ & 49 & $56 \%$ \\
\hline Quinta-feira & $18: 00$ & 45 & $62 \%$ \\
\hline Quinta-feira & $21: 00$ & 10 & $38 \%$ \\
\hline Sexta-feira & 08:00 & 12 & $15 \%$ \\
\hline \multirow[t]{2}{*}{ Sexta-feira } & $15: 00$ & 24 & $52 \%$ \\
\hline & & $\begin{array}{c}337 \\
\text { (total) }\end{array}$ & $\begin{array}{c}47 \% \\
\text { (média) }\end{array}$ \\
\hline
\end{tabular}

Fonte: Os autores.

Tabela 2. Dias, horários, número de pessoas e porcentagem do espaço de análise utilizado pelas pessoas - Estacionamentos $2 \mathrm{~A}$ e $2 \mathrm{~B}$

\begin{tabular}{|c|c|c|c|}
\hline \multicolumn{4}{|c|}{ Estacionamento $2 \mathrm{~A}$} \\
\hline Dia & Horário & $\mathrm{N}^{\circ}$ de pessoas & Porcentagem \\
\hline Segunda-feira & 08:00 & 9 & $58 \%$ \\
\hline Segunda-feira & $15: 00$ & 12 & $41 \%$ \\
\hline Terça-feira & $12: 00$ & 18 & $49 \%$ \\
\hline Terça-feira & $18: 00$ & 24 & $64 \%$ \\
\hline Terça-feira & $21: 00$ & 6 & $40 \%$ \\
\hline Quarta-feira & 08:00 & 10 & $55 \%$ \\
\hline Quarta-feira & $15: 00$ & 12 & $59 \%$ \\
\hline Quinta-feira & $12: 00$ & 17 & $51 \%$ \\
\hline Quinta-feira & $18: 00$ & 16 & $60 \%$ \\
\hline Quinta-feira & $21: 00$ & 7 & $32 \%$ \\
\hline Sexta-feira & 08:00 & 3 & $28 \%$ \\
\hline Sexta-feira & $15: 00$ & 5 & $52 \%$ \\
\hline & & $\begin{array}{c}139 \\
\text { (total) }\end{array}$ & $\begin{array}{c}49 \% \\
\text { (média) }\end{array}$ \\
\hline \multicolumn{4}{|c|}{ Estacionamento 2B } \\
\hline Dia & Horário & $\mathrm{N}^{\circ}$ de pessoas & Classificação \\
\hline Segunda-feira & $08: 00$ & 15 & 2 \\
\hline Segunda-feira & $15: 00$ & 13 & 2 \\
\hline Terça-feira & $12: 00$ & 32 & 3 \\
\hline Terça-feira & $18: 00$ & 46 & 4 \\
\hline Terça-feira & $21: 00$ & 2 & 1 \\
\hline Quarta-feira & 08:00 & 16 & 2 \\
\hline Quarta-feira & $15: 00$ & 22 & 2 \\
\hline Quinta-feira & $12: 00$ & 32 & 3 \\
\hline Quinta-feira & $18: 00$ & 32 & 3 \\
\hline Quinta-feira & $21: 00$ & 13 & 2 \\
\hline Sexta-feira & 08:00 & 14 & 2 \\
\hline \multirow[t]{2}{*}{ Sexta-feira } & $15: 00$ & 7 & 1 \\
\hline & & $\begin{array}{c}244 \\
\text { (total) }\end{array}$ & $\begin{array}{c}2,3 \\
\text { (média) }\end{array}$ \\
\hline
\end{tabular}

Fonte: Os autores. 


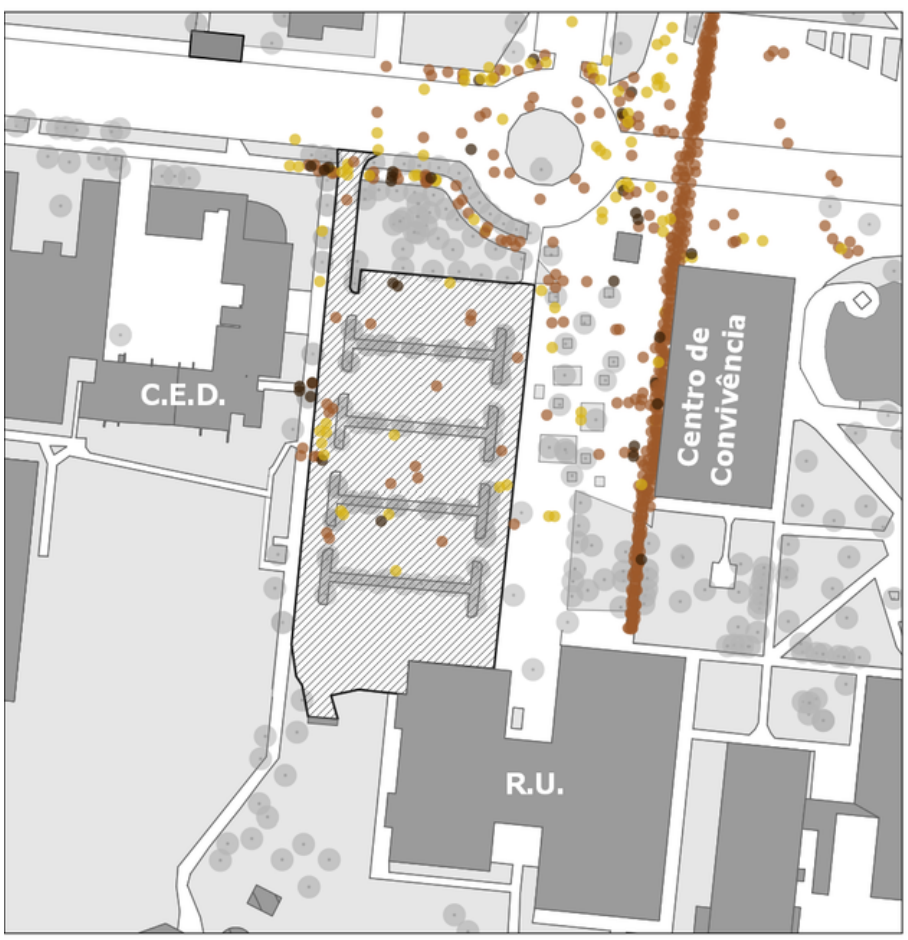

a) Estacionamento $1 \mathrm{~A}$
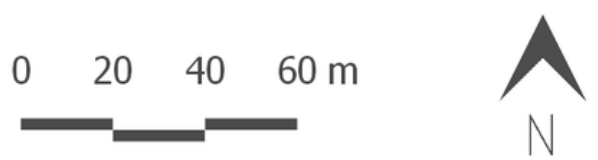

Fonte: Os autores.

$\mathrm{Na}$ Tabela 2, vemos que o estacionamento $2 \mathrm{~A}$ não apresentou em nenhum momento um grande número de pessoas circulando. De outra parte, no estacionamento $2 \mathrm{~B}$, é possível perceber que existe uma movimentação constante de pessoas pelo local de análise, sendo maior a concentração de pessoas nos horários das 12:00 e 18:00 horas. A constante movimentação de pessoas pode estar associada à proximidade do estacionamento $2 \mathrm{~B}$ da Reitoria e ao fato de estar em um local central do campus.

Uma análise mais detida sobre os padrões de utilização do espaço em cada par (Figuras 7 e 8) mostra que, em ambos os casos, há uma maior quantidade de pessoas transitando por dentro do estacionamento naqueles com menor quantidade de crimes (1B e 2B). No caso do estacionamento $1 \mathrm{~A}$, as pessoas concentram-se nos dois eixos de circulação principais, um deles junto à rua e o outro em direção ao RU. Já no estacionamento da BU (1B), além de haver grande concentração de pessoas nos caminhos ao seu redor, há também uma quantidade significativa de pessoas passando pelo seu interior, na

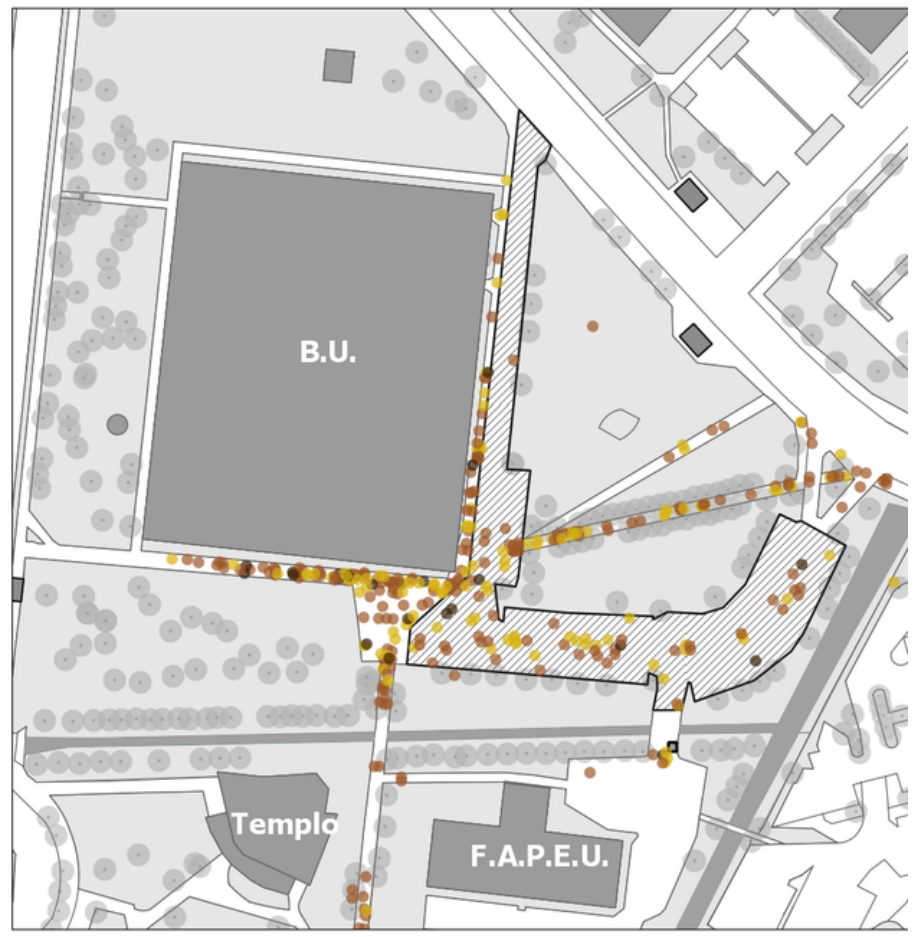

b) Estacionamento $1 \mathrm{~B}$

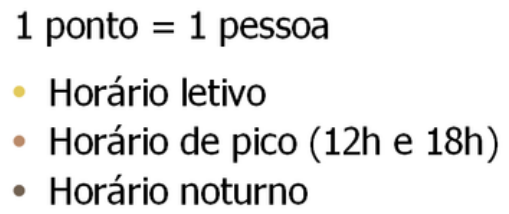

direção de uma das conexões do campus com a rua. Os estacionamentos $2 \mathrm{~A}$ e $2 \mathrm{~B}$ possuem grande quantidade de pessoas circulando no seu interior, mas a forma do estacionamento $2 \mathrm{~A}$ faz com que uma porção significativa de pessoas fique atrás do fórum e, portanto, distante de qualquer fluxo de passagem. Chama a atenção também a proximidade do caminho na lateral no estacionamento $2 \mathrm{~B}$, o que provavelmente facilita a vigilância natural daqueles que não trafegam por dentro do estacionamento, em contraste com a distância dos caminhos no caso 1A, pertencente ao outro par.

A Figura 9 mostra uma sobreposição das isovistas dos principais caminhos em cada local dos estacionamentos 2A e 2B. Ela foi elaborada com base em uma distância arbitrária de 10 metros para cada ponto gerador de isovista ao longo dos principais percursos. Atribuindo transparência a cada polígono de isovista, conseguimos representar os locais em que há maior sobreposição com cores mais escuras, e locais com pouca ou nenhuma sobreposição de isovistas em cores claras. 
Figura 8. Apropriação no par de estacionamentos 2

\section{MAPAS DE APROPRIACẼO}

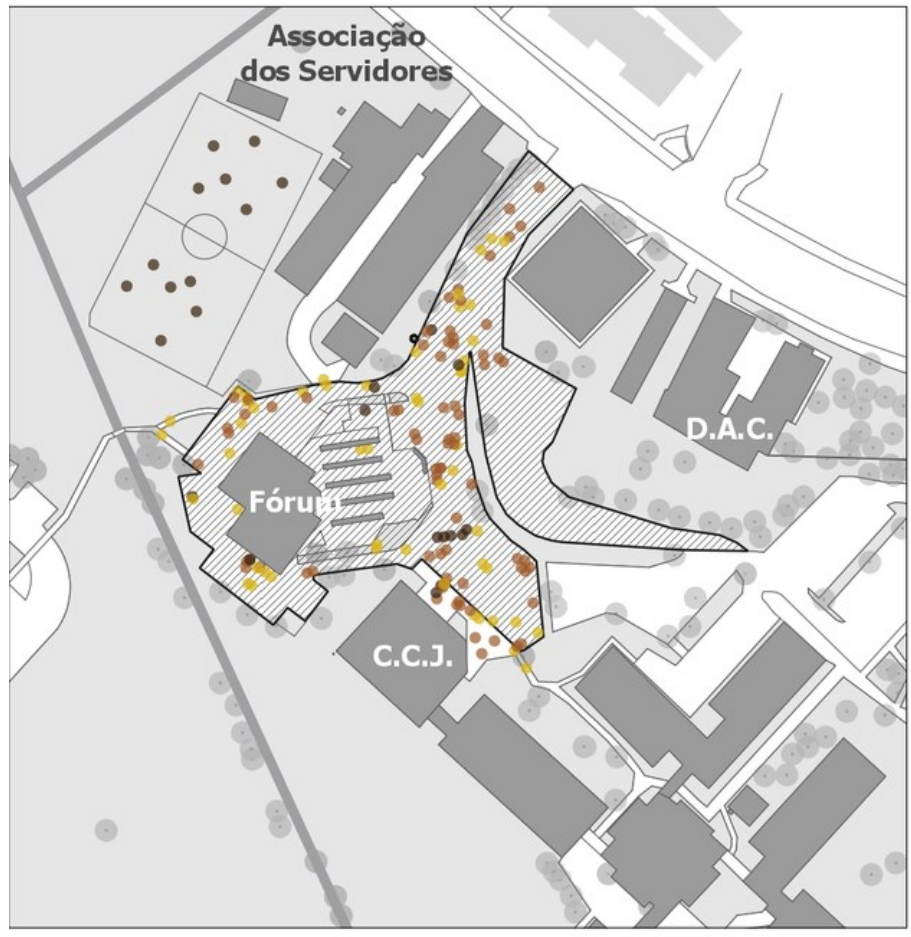

a) Estacionamento $2 \mathrm{~A}$
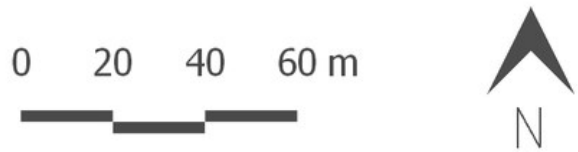

Fonte: Os autores

$\mathrm{Na}$ Figura 9, fica clara a diferença entre porções do estacionamento $2 \mathrm{~A}$, que permanecem pouco visíveis a partir dos caminhos, e o estacionamento $2 \mathrm{~B}$, cuja área é toda bastante visível a partir dos caminhos adjacentes.

No Gráfico 3, a seguir, vemos que os dois pares de estacionamentos apresentaram, em cada estacionamento, valores inversos aos esperados no que se refere à quantidade de pessoas transitando e valores muito próximos referentes à proporção do espaço apropriado por elas, o que sugere que a quantidade em si não é o fator determinante, mas sim o modo como essas pessoas estão distribuídas em relação ao estacionamento, ou seja, se estão passando por dentro ou junto dele ou se, ao contrário, passam por caminhos mais distantes.

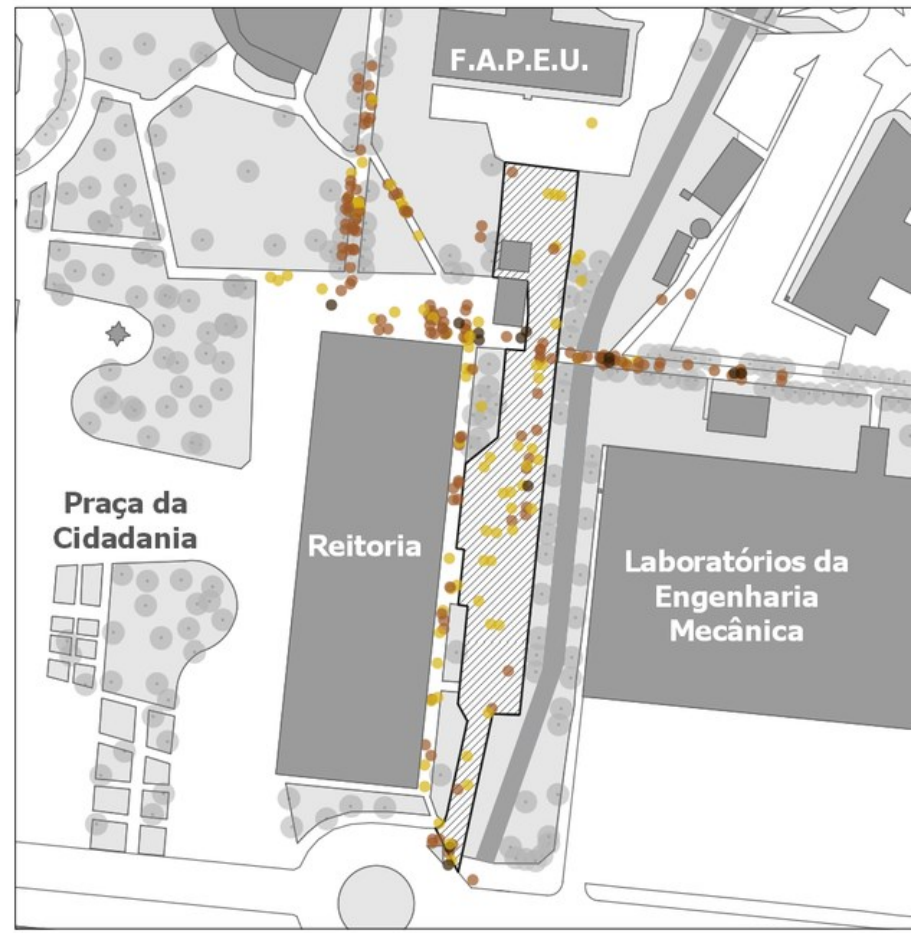

b) Estacionamento $2 \mathrm{~B}$
1 ponto = 1 pessoa
- Horário letivo
- Horário de pico (12h e 18h)
- Horário noturno

Figura 9. Isovistas caminhos do entorno dos estacionamentos $2 \mathrm{~A}$ e $2 \mathrm{~B}$ MAPAS DE ISOVISTAS A PARTIR DE TRAJETOS

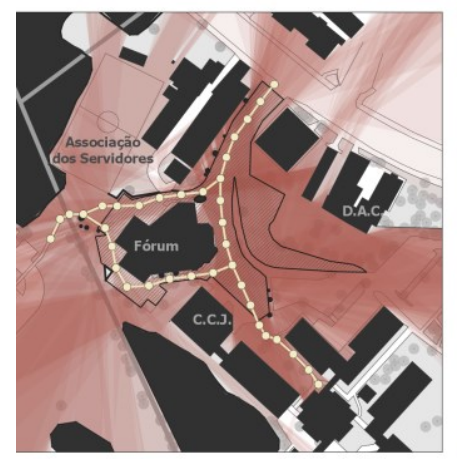

a) Estacionamento $2 \mathrm{~A}$

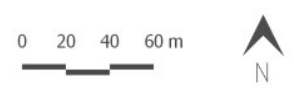

Fonte: Os autores.

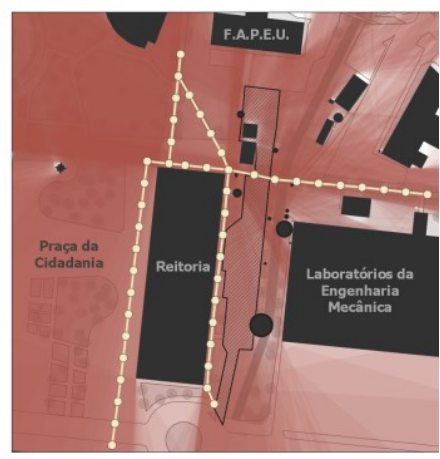

b) Estacionamento 2B

- Barreiras à visibilidade Pontos de análise da Isovista $(10 \mathrm{em} 10 \mathrm{~m})$ 
Gráfico 3. Valores proporcionais obtidos nos dois pares de estacionamentos pesquisados em relação a) à quantidade de pessoas; e b) à porcentagem da área utilizada pelas pessoas
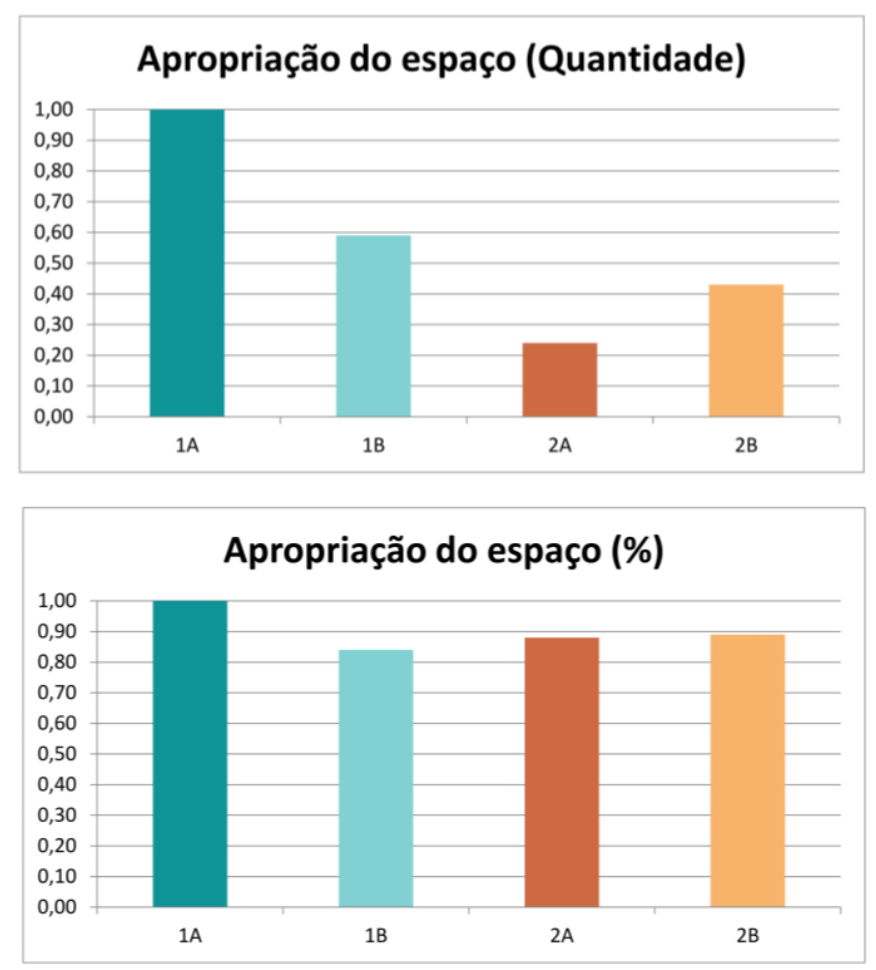

Fonte: Os autores.

\section{Variedade de usos do solo}

Na Figura 10 são apresentadas as edificações do entorno dos estacionamentos $1 \mathrm{~A}$ e $1 \mathrm{~B}$, sendo descritos seus usos do solo e seus horários de funcionamento. Nessa Figura, notamos que o estacionamento $1 \mathrm{~A}$ possui quatro edificações no seu entorno com categorias de uso do solo distintas. Uma dessas edificações é o Restaurante Universitário - RU, local muito utilizado durante o seu horário de funcionamento, formando grandes filas.

Figura 10. Uso do solo das edificações do entorno do estacionamento $1 \mathrm{~A}$ e $1 \mathrm{~B}$ MAPAS DE USO DO SOLO

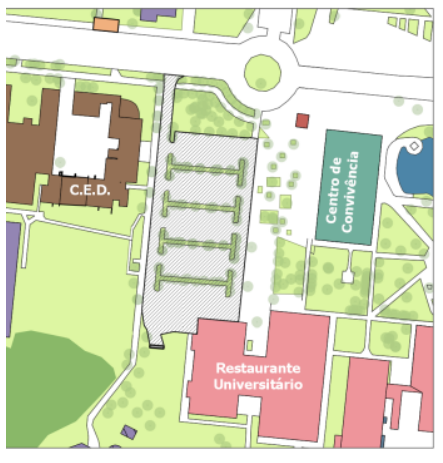

a) Estacionamento $1 \mathrm{~A}$
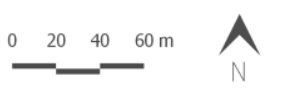

$\square$ Pontos de ônibus
UA - Uso Administrativo
UB - Uso Biblioteca Univer -UC - Uso Biblioteca

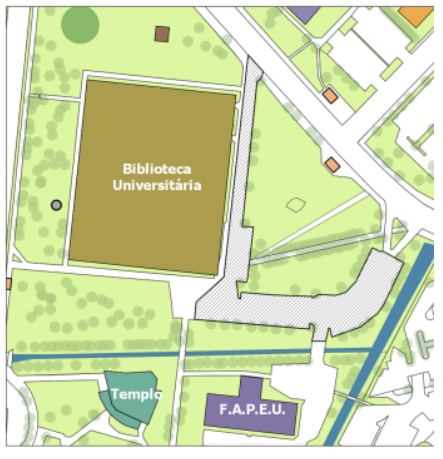

b) Estacionamento $1 \mathrm{~B}$
Fonte: Os autores.

No estacionamento 1B, mostrado na Figura 10, percebemos que o estacionamento tem no seu entorno apenas três edificações com categorias de uso do solo distintas, sendo uma das edificações a Biblioteca Universitária - BU, local também muito utilizado durante todo o dia, proporcionando grande fluxo de pessoas.

No que se refere aos estacionamentos $2 \mathrm{~A}$ e $2 \mathrm{~B}$, mostrados na Figura 11, percebemos que o estacionamento 2A possui quatro edificações no seu entorno com categorias de uso do solo distintas, enquanto que o estacionamento $2 \mathrm{~B}$ tem no seu entorno três edificações.

Figura 11. Uso do solo das edificações do entorno dos estacionamentos $2 \mathrm{~A}$ e $2 \mathrm{~B}$ MAPAS DE USO DO SOLO

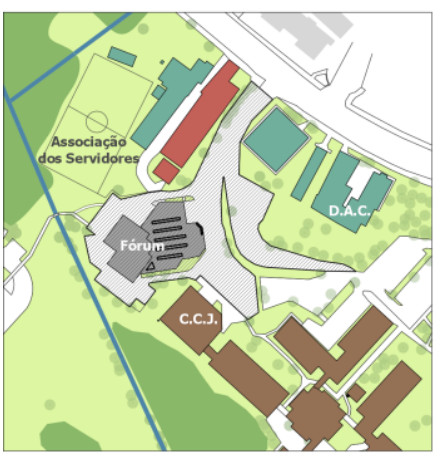

a) Estacionamento $2 \mathrm{~A}$

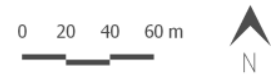

Fonte: Os autores.

No Gráfico 4 vemos que, nos dois pares, os estacionamentos $1 \mathrm{~B}$ e $2 \mathrm{~B}$, com menor número de ocorrências, apresentam menor variedade de uso do solo no entorno dos estacionamentos que seus respectivos pares. Isso sugere uma relação entre a menor variedade de usos do solo e menores índices de ocorrências de crimes. Isso talvez possa ser explicado pelo fato de que o uso do solo diversificado, apesar de tender a atrair mais pessoas e, com isso, gerar maior vigilância natural, por outro lado provavelmente aumenta o anonimato dos espaços $\mathrm{e}$ diminui a sensação de territorialidade que poderia conferir um certo sentimento de legitimidade para exercer essa vigilância. De qualquer forma, é importante destacar que os estacionamentos 1B e 2B possuem em seu entorno usos que atraem grande quantidade de pessoas, como a Biblioteca Universitária e a Reitoria. Assim, mesmo tendo menor diversidade de usos do solo, apresentam quantidades de pessoas muito próximas das registradas nos estacionamentos $1 \mathrm{~A}$ e $2 \mathrm{~A}$, conforme apresentado anteriormente. 
Gráfico 4. Valores proporcionais (1 para a maior quantidade de usos diferentes encontrados) obtidos nos dois pares de estacionamentos pesquisados em relação à diversidade de usos do solo

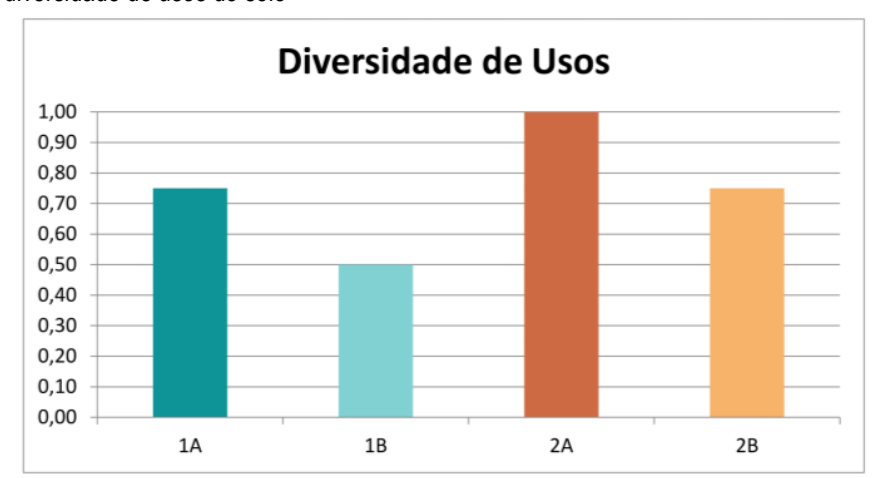

Fonte: Os autores.

\section{Iluminação}

A Figura 12 mostra o posicionamento dos pontos de iluminação dos estacionamentos $1 \mathrm{~A}$ e $1 \mathrm{~B}$ e a área iluminada por esses pontos. A densidade de iluminação no primeiro é de 0,002 , apenas $50 \%$ da área do estacionamento iluminada, enquanto que para o segundo esses valores são de 0,005 e $65 \%$. Portanto, é maior a densidade de pontos de luz e área iluminada no estacionamento $1 \mathrm{~B}$ do que no estacionamento $1 \mathrm{~A}$.

Figura 12. lluminação nos estacionamentos $1 \mathrm{~A}$ e $1 \mathrm{~B}$ MAPAS DE ILUMINACẼO

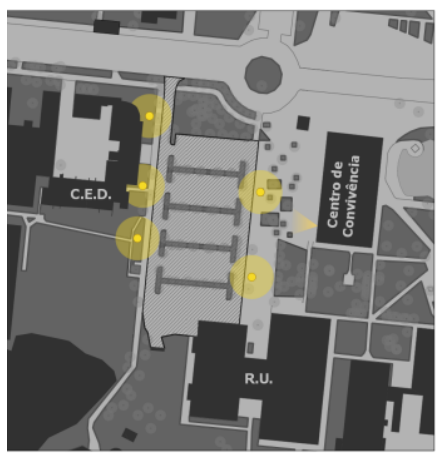

a) Estacionamento $1 \mathrm{~A}$

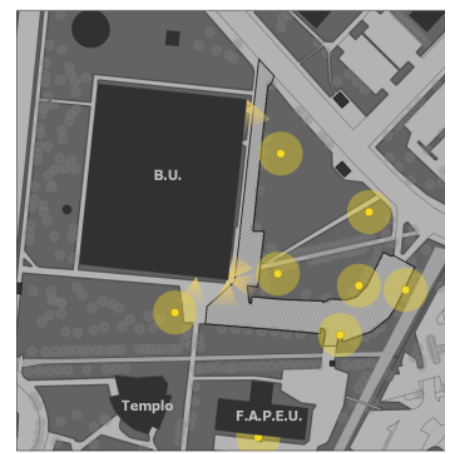

$0 \quad 20 \quad 40 \quad 60 \mathrm{~m}$

b) Estacionamento $1 \mathrm{~B}$

Legenda

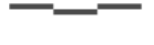

Fonte: Os autores.

No tocante ao par de estacionamentos 2A e 2B (Figura 13), o primeiro possui densidade de iluminação de 0,005 e área iluminada de $95 \%$ da área total, enquanto que para o segundo esses valores correspondem a 0,010 e $85 \%$.

Tais resultados sugerem a existência de uma relação entre a maior densidade de pontos de luz, a porcentagem de área do estacionamento iluminada e menores índices de ocorrências de crime de furto e roubo de/em veículos, ainda que no caso do estacionamento $2 \mathrm{~A}$, este tenha apresentado uma porcentagem de área do estacionamento iluminada maior que a do $2 \mathrm{~B} \quad(95 \%$ e $85 \%$, respectivamente).

Figura 13. lluminação nos estacionamentos $2 \mathrm{~A}$ e $2 \mathrm{~B}$ MAPAS DE ILUMINACẼO

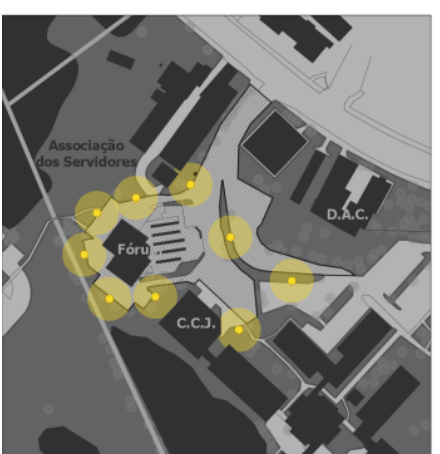

a) Estacionamento $2 \mathrm{~A}$

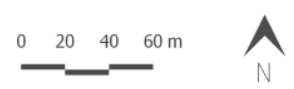

Fonte: Os autores

\section{Recursos de vigilância}

O estacionamento 1A possui apenas uma câmera de segurança e um vigia que faz ronda pelos edifícios do entorno e pelo estacionamento. Apenas 3\% da área do estacionamento é visível por meio da câmera instalada. No estacionamento $1 \mathrm{~B}$, há duas câmeras de segurança e duas pessoas fazem a vigilância; a mesma situação acontece no estacionamento $2 \mathrm{~A}$, enquanto que o $2 \mathrm{~B}$ possui um total de sete câmeras de segurança, cobrindo $88 \%$ da área do estacionamento. Dessa forma, foi possível detectar a existência de uma relação entre a maior quantidade de recursos de segurança e porcentagem de área visível por recursos de segurança, e menores índices de ocorrências de crimes nesses locais.

\section{Sobreposição das variáveis}

Por fim, os Gráficos 5 e 6 apresentam os valores proporcionais das quatro variáveis analisadas, obtidos nos quatro estacionamentos, mostrando cada estacionamento do mesmo par sobreposto ao outro. Neles, vemos que os locais de análise com maiores ocorrências de furto e roubo de/em veículos possuem baixa visibilidade, apresentando bastantes barreiras visuais e pouca possibilidade de intervisibilidade. Também é possível perceber que esses dois estacionamentos apresentaram variedade de uso do solo maior do que os estacionamentos com menos ocorrências. Em relação à quantidade de pessoas e à apropriação do espaço por elas, os resultados se mantiveram semelhantes. No que se refere à permeabilidade, os estacionamentos $1 \mathrm{~B}$ e $2 \mathrm{~B}$, com menores ocorrências, apresentaram maior integração. 
Gráfico 5. Valores proporcionais obtidos em cada variável analisada dos estacionamentos $1 \mathrm{~A}$ e $1 \mathrm{~B}$. VIS: visibilidade; PER: permeabilidade (integração); APQ: quantidade de pessoas; APP: porcentagem da área ocupada por pessoas; USO: diversidade de usos

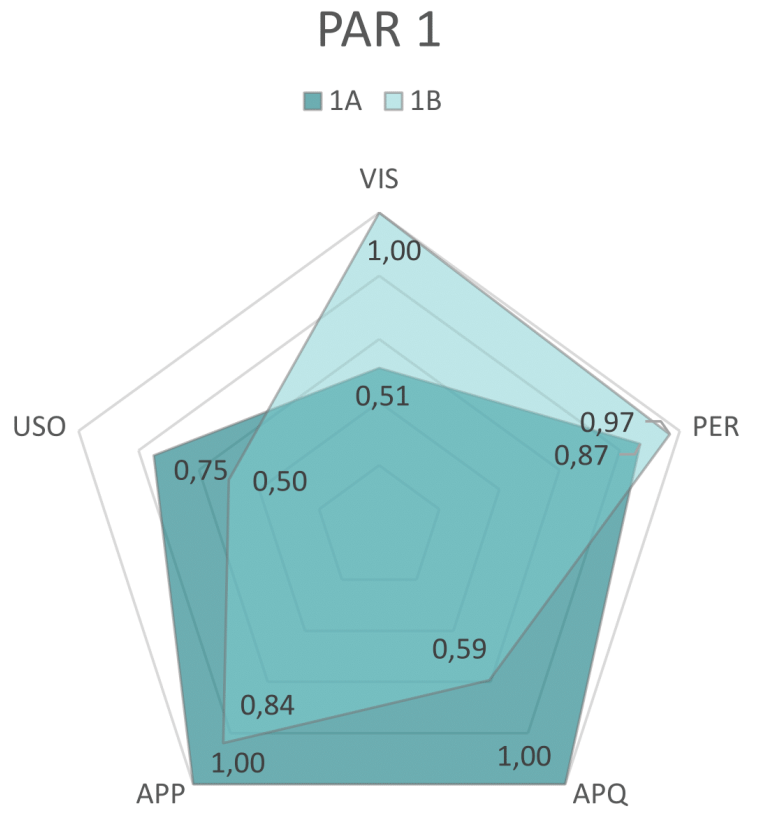

Fonte: Os autores.

Gráfico 6. Valores proporcionais obtidos em cada variável analisada dos estacionamentos 2A e 2B. VIS: visibilidade; PER: permeabilidade (integração); APQ: quantidade de pessoas; APP: porcentagem da área ocupada por pessoas; USO: diversidade de usos

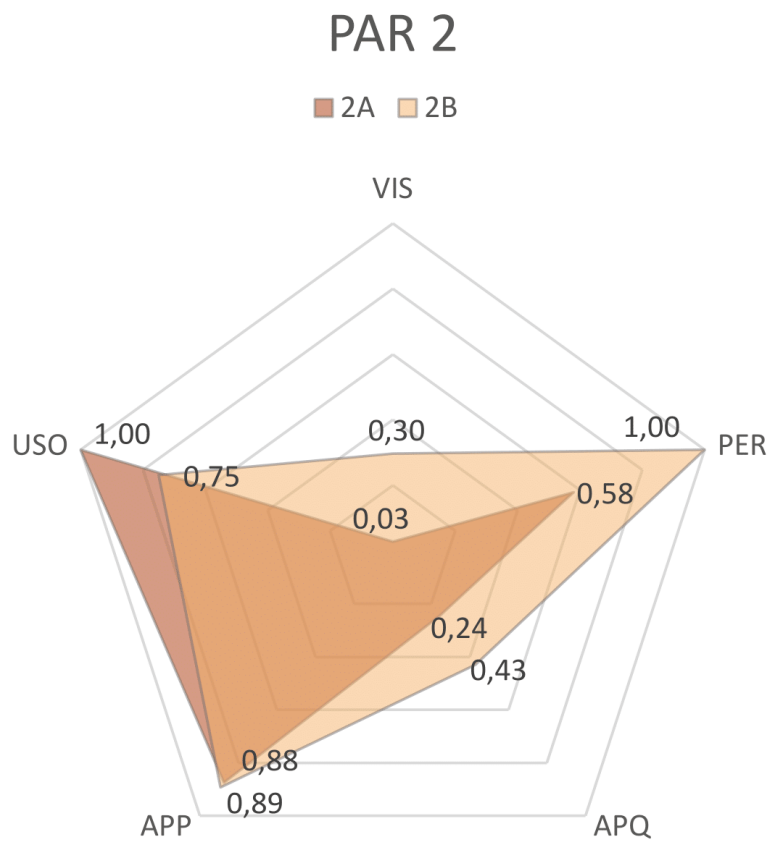

Fonte: Os autores

\section{Conclusão}

A premissa de que a ocorrência de crimes é mais frequente em áreas que apresentam configuração espacial com menor campo de visão, com mais barreiras visuais e menor intervisibilidade entre as pessoas foi suportada pelos resultados obtidos neste estudo, uma vez que os estacionamentos com menores índices de ocorrências de furto e roubo de/em veículos apresentaram maiores áreas de isovista se comparados aos seus pares com maior número de ocorrências desses crimes.

Com relação à premissa de que locais com maior número de pessoas transitando e maior apropriação do espaço por essas pessoas tendem a ter menos ocorrências, não foi possível estabelecer nenhuma relação significativa, uma vez que os estacionamentos com maiores e menores números de ocorrências apresentaram valores semelhantes em seus resultados. Entretanto, os casos analisados sugerem uma forte relação do estacionamento com os principais eixos de circulação do local. Uma recomendação preliminar derivada deste estudo, a ser testada em outros trabalhos e confrontada com outros requisitos e intenções de projeto, é que estacionamentos que realizam ligações importantes dentro da estrutura do campus, e, portanto, são usados como caminhos pelos pedestres, tendem a ser mais seguros. Por isso, essas soluções projetuais poderiam ser incentivadas. Complementarmente, ou se isso não for possível, é recomendável que o estacionamento esteja posicionado a uma distância relativamente próxima dos eixos de circulação do entorno.

A premissa de que os crimes tendem a acontecer em áreas com menor variedade de uso do solo não foi confirmada por este trabalho, pois os estacionamentos com maiores ocorrências de furto e roubo de/em veículos estão em áreas com maior variedade de uso do solo. Entretanto, o tipo de uso do solo parece ser relevante, uma vez que os dois estacionamentos com menor número de ocorrências estão próximos de edificações bastante utilizadas durante todo o período do dia: reitoria e biblioteca universitária. Portanto, uma distribuição mais uniforme ao longo do dia parece ser mais significativa do que a quantidade absoluta de pessoas.

Os estudos dos usos sugerem também a necessidade de aprofundar a análise da diversidade de pessoas que frequentam um determinado local do campus, e o quanto isso pode, supostamente, aumentar ou diminuir a capacidade e o senso de legitimidade dos usuários de reconhecer e exercer algum controle uns sobre os outros. Há que se ter o cuidado, no entanto, de não cair na alternativa fácil da defesa da segregação e do isolamento, uma vez que a diversidade de usuários pode ser um fator de incentivo à criatividade e ao intercâmbio de conhecimentos e experiências mais ricas e complexas. 
Por fim, a premissa de que locais com maior permeabilidade tendem a ter menos ocorrências de crime encontrou suporte nos resultados obtidos, visto que os dois estacionamentos com menor ocorrência dos crimes de furto e roubo de/em veículos apresentaram maior integração.

Em relação às variáveis de controle, tanto a melhor iluminação do estacionamento, quanto o maior controle por recursos de vigilância, parecem contribuir para um menor número de furto e roubo de/em veículos.
Esperamos que esta pesquisa possa contribuir para o maior conhecimento dos impactos de aspectos da configuração física dos espaços na ocorrência de crimes em campi universitários, de tal modo que as construções e intervenções no espaço físico sejam realizadas com um planejamento criterioso e maior compreensão dos seus efeitos. Com base nisso, é possível vislumbrar cenários que abordem a segurança como elemento qualificador do ambiente construído, tema ainda pouco abordado nos campi universitários, mas de fundamental importância para a vitalidade desses espaços tão singularmente ocupados.

\section{Agradecimentos}

Programa de Educação Tutorial - Ministério da Educação; Secretaria de Segurança Institucional - UFSC; Departamento de Projetos de Arquitetura e Engenharia - UFSC.

\section{Notas}

(1) Os valores mostrados nos Gráficos foram calculados da seguinte maneira: o valor máximo encontrado nos quatro estacionamentos foi considerado como igual a 1; os demais valores foram calculados em proporção a esse valor máximo. Isso teve o objetivo de padronizar as escalas de cada variável para permitir a comparação simultânea feita nos Gráficos 5 e 6.

\section{Referências}

BONDARUK, Roberson Luiz. A Prevenção do crime através do desenho urbano. 2. ed. Curitiba: Edição do autor, 2007.

CALDEIRA, T. Cidade de muros: Crime, segregação e cidadania em São Paulo. São Paulo: USP, 2000.

CLARKE, R.; CORNISH, D. B. Modeling offenders' decisions: a framework for research and policy. In: ANDRESEN, M. A.; BRANTINGHAM, P. J.; KINNEY, J. B. (Eds.). Classics in Environmental Criminology. Hoboken: CRC Press, 2010 [1985]. p. 311-340.

COHEN, L. E.; FELSON, M. Social Change and Crime Rate Trends: A Routine Activity Approach. In: ANDRESEN, M. A.; BRANTINGHAM, P. J.; KINNEY, J. B. (Eds.). Classics in Environmental Criminology. Hoboken: CRC Press, 2010 [1979]. p. $187-216$.

COZENS, Paul Michael; SAVILLE, Greg; HILLIER, David. Crime prevention through environmental design (CPTED): a review and modern bibliography. Property Management, v. 23, n. 5, p.328-356, 2005. ISSN 0263-7472

https://doi.org/10.1108/02637470510631483

HILLIER, B. et al. Natural movement: or, configuration and attraction in urban pedestrian movement. Environment and Planning B: Planning and Design, v. 20, n. 1, p. 29-66, 1993. ISSN 2399-8083. https://doi.org/10.1068/b200029

JACOBS, Jane. Morte e vida de grandes cidades. São Paulo: Martins Fontes, 2001. (publicado originalmente em 1961 com o título: Life and Death of Great American Cities).

NEWMAN, Oscar. Defensible Space. Crime Prevention Through Urban Design. New York: Collier Books/Macmillan Publishing Co., Inc., 2. ed. 1976.

NEWMAN, Oscar. Personal email to Stephen Town, Police Architectural Liaison Officer, Bradford District, dez.2003.

QUINTANA, Efreu Brignol. Influência de características físico-espaciais na ocorrência de crimes e na percepção de segurança em áreas residenciais com condomínios fechados. 2013. 290f.. Dissertação (Mestrado em Arquitetura e Urbanismo) Programa de Pós-Graduação em Planejamento Urbano e Regional, Universidade Federal do Rio Grande do Sul, Porto Alegre. 
SABOYA, Renato Tibiriçá de; BANKI, Gabriela Hall; SANTANA, Júlia Mayer Alves de. Uso do solo, visibilidade e ocorrência de crimes: um estudo de caso em Florianópolis, Santa Catarina. Oculum ens., Campinas, 13(2), 255-274, Julho-Dezembro 2016. ISSNe 2318-0919. https://doi.org/10.24220/2318-0919v13n2a2990

SORENSEN, David. The nature and prevention of residential burglary: A review of the international literature with an eye towards prevention in Denmark. 2003. Disponível em:

$<$ http://www.justitsministerietdk/sites/default/files/media/Arbejdsomraader/Forskning/Forskningspuljen/2011/2003/The Nature an d Prevention of Residential_Burglary.pdf $>$ Acesso em: 15 jun. 2015.

VIVAN, Mariana. Arquitetura, espaço urbano e criminalidade: relações entre o espaço construído e a segurança sob a ótica da intervisibilidade. 2012. 191f.. Dissertação (Mestrado em Arquitetura e Urbanismo) - Programa de Pós-Graduação em Arquitetura e Urbanismo, Universidade Federal de Santa Catarina, Florianópolis.

WILCOX, Pamela; LAND, Kenneth C.; HUNT, Scott A. Criminal circumstance: a dynamic multicontextual criminal opportunity theory. Rev. ed. New York: Walter de Gruyter, Inc, 2003.

WORTLEY, Richard; MAZEROLLE, Lorraine. Environmental criminology and crime analysis: situating the theory, analytic approach and application. In: WORTLEY, R.; MAZEROLLE, L. G. (Eds.). Environmental criminology and crime analysis. Crime science series. Cullompton, UK: Willan, 2008.

ZANOTTO, Karen da Rosa. Segurança em área urbana central: Configuração, Forma Urbana e Usuários. 2002. 161f.. Dissertação (Mestrado em Arquitetura e Urbanismo) - Programa de Pós-Graduação em Planejamento Urbano e Regional, Universidade Federal do Rio Grande do Sul, Porto Alegre.

\title{
${ }^{1}$ Mariana Soares
}

Arquiteta e Urbanista. Doutora. Campus Reitor João David Ferreira Lima, Trindade, Florianópolis, SC, Brasil, CEP: 88040-900.

\section{${ }^{2}$ Gabriel George Grosskopf}

Estudante. Graduação em Arquitetura e Urbanismo. Campus Reitor João David Ferreira Lima, Trindade, Florianópolis, SC, Brasil, CEP: 88040-900.

\section{${ }^{3}$ Julia Roberta Eli}

Estudante. Graduação em Arquitetura e Urbanismo. Campus Reitor João David Ferreira Lima, Trindade, Florianópolis, SC, Brasil, CEP: 88040-900.

\author{
${ }^{4}$ Renato Tibiriçá de Saboya \\ Arquiteto e Urbanista. Doutor. Campus Reitor João David Ferreira Lima, Trindade, Florianópolis, SC, Brasil, CEP: 88040-900.
}

\section{${ }^{5}$ Fernando Barth}

Engenheiro Civil. PhD. Campus Reitor João David Ferreira Lima, Trindade, Florianópolis, SC, Brasil, CEP: 88040-900. 